\title{
On a model simulating lack of hydraulic connection between a man-made reservoir and the volume of poroelastic rock hosting the focus of a post-impoundment earthquake
}

\author{
RAMESH CHANDER ${ }^{1}$ and S K TOMAR ${ }^{2, *}$ \\ ${ }^{1}$ No. 290 Sector - 4, Mansa Devi Complex, Panchkula 134 114, India. \\ ${ }^{2}$ Department of Mathematics, Panjab University, Chandigarh 160 014, India. \\ *Corresponding author. e-mail: sktomar66@gmail.com
}

\begin{abstract}
The idea that a direct hydraulic connection between a man-made reservoir and the foci of postimpoundment earthquakes may not exist at all sites is eminently credible on geological grounds. Our aim is to provide a simple earth model and related theory for use during investigations of earthquakes near new man-made reservoirs. We consider a uniform circular reservoir which rests on the top surface of a no-hydraulic-connection earth model (NHCEM). The model comprises a top elastic (E) layer, an intermediate poroelastic (P) layer, and a bottom elastic half space. The focus of a potential earthquake in the $\mathrm{P}$ layer is located directly under the reservoir. The $\mathrm{E}$ layer disrupts the hydraulic connection between the reservoir and the focus. Depth of water in the reservoir varies as $H^{\prime}+h \cos (\omega t)$. Expressions for reservoir-induced stresses and pore pressure in different layers of the NHCEM are obtained by solving the boundary-value problem invoking full coupling between mean normal stress and pore pressure in the $\mathrm{P}$ layer. As an application of the derived mathematical results, we have examined and found that earthquakes on $60^{\circ}$ normal faults may occur in the P-layer of a selected NHCEM at epochs of low reservoir level if the reservoir lies mostly in the footwall of the fault. The exercise was motivated by observations of such earthquakes under the man-made Lake Mead after it was impounded.
\end{abstract}

\section{Introduction}

The hazard and safety concerns as well as good engineering and scientific practice require that each new episode of earthquakes near man-made reservoirs (ENMRs) be investigated. Such investigations at present are carried out using assumed simple earth models because adequate information about subsurface geology up to earthquake depths under a reservoir is not available in general. We distinguish here between a full-hydraulic-connection earth model (FHCEM) and a no-hydraulic-connection earth model (NHCEM). In the two main examples of FHCEM in current use, it is assumed that porous-elastic rock(s) (Roeloffs 1988) or a system of fractures in rock (Snow 1972) provide hydraulic connection between the reservoir and the focus of a post-impoundment earthquake. Here, we describe a procedure to evaluate the response of a three-layered NHCEM to the load of a circular reservoir with oscillating water level.

The top E layer of the NHCEM (figure 1a) is elastic and much thicker than the intermediate poroelastic $(\mathrm{P})$ layer. The bottom layer, an elastic half space, is called the $\mathrm{H}$ layer. The focus of a potential earthquake is located in the $\mathrm{P}$ layer. We

Keywords. Earthquake hazard; man-made reservoirs; reservoir-influenced seismicity; tectonic earthquakes; fault stability; Lake Mead seismicity. 


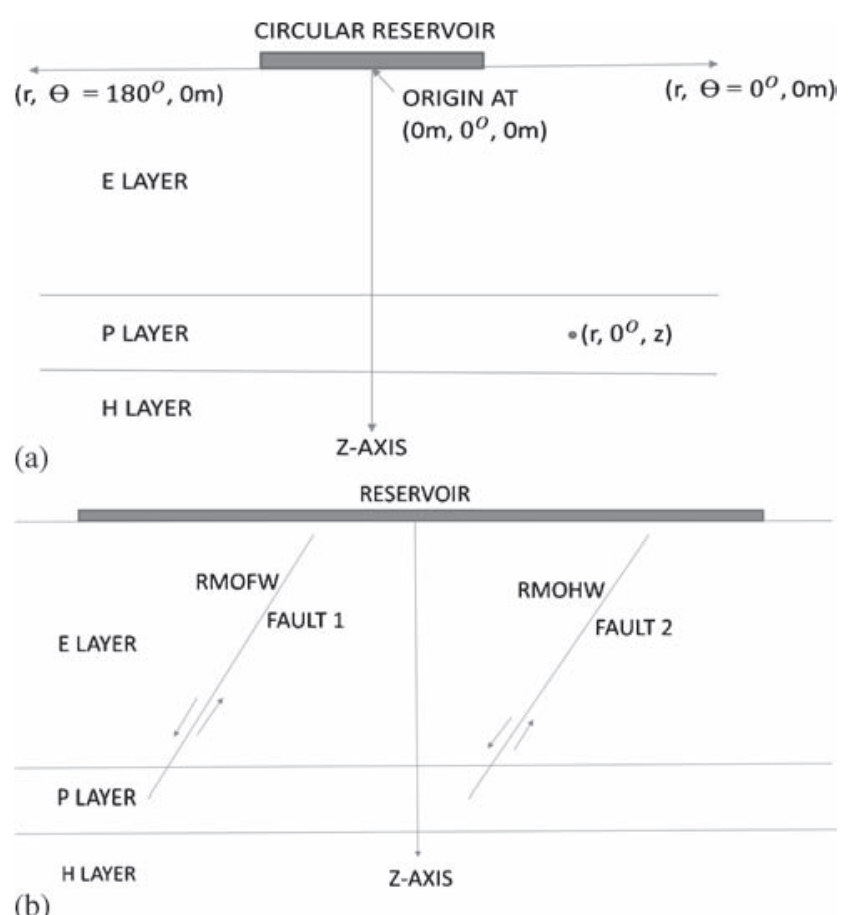

(b)

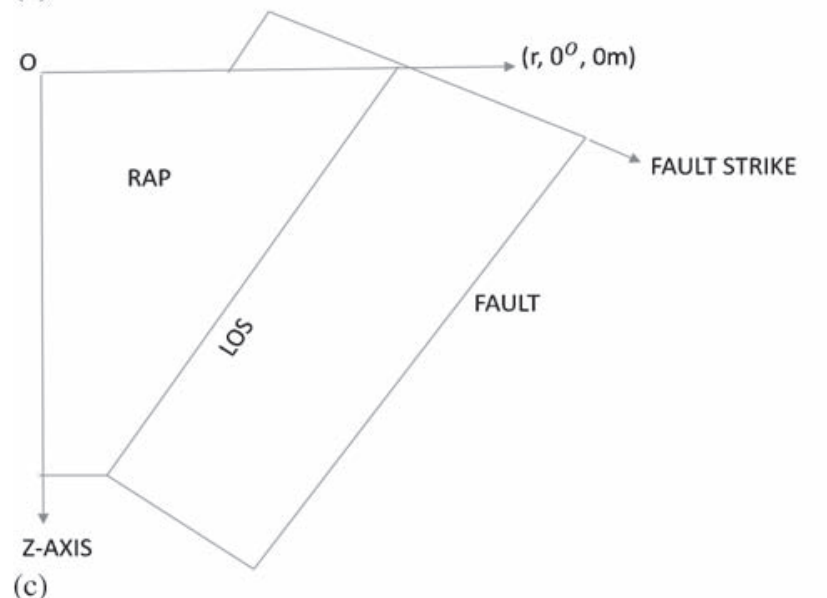

(c)

Figure 1. (a) A schematic cross-sectional representation of an NHCEM under a circular reservoir. The origin $\mathrm{O}$ and the z-axis of an $(r, \theta, z)$ cylindrical coordinate system are shown. The plane of the figure is called 'reference axial plane' (RAP). (b) The concept of reservoir mostly on the footwall (RMOFW) and reservoir mostly on the hanging wall (RMOHW) of a normal fault is indicated. (c) When the strike of a fault is normal to RAP, the line of symmetry (LOS) of the fault is the line of its intersection with the RAP.

concentrate on positions of the focus directly under the reservoir.

So far, all earthquakes observed near man-made reservoirs have been tectonic earthquakes that occur most commonly due to renewed slip on preexisting faults (Richter 1957). Hubbert and Rubey (1959) argued that pore fluids in rocks on two sides of a fault facilitate slip by reducing friction. The $\mathrm{P}$ layer represents water-filled rock around earthquake focus. The E layer, being non-porous and impermeable, disrupts the hydraulic connection between the reservoir and the earthquake focus.
The simplest example of a NHCEM is an ideal elastic half space. The response of this model to surface loads is well known due to the work of Boussinesq (Love 1944; Jaeger and Cook 1969). Response of an NHCEM in which a pocket of poroelastic rock is embedded in an elastic half space deserves inquiry. But we consider a poroelastic layer embedded in an elastic half space because the analytical treatment is vastly simpler.

Reservoir weight and hydraulic pressure at its bottom both influence stress and pore pressure inside a FHCEM (e.g., Roeloffs 1988), while only the weight of the reservoir exerts influence within the NHCEM.

Beginning with Haskell (1953), numerous multilayered models have been used to explain observations in different disciplines of earth science. Wang (2000) discusses instances where models with one or more poroelastic layers have been considered in geo-mechanics, hydrogeology and petroleum engineering. Segall's (1985) model is the closest to ours in that both involve deformation of a threelayered earth. However, Segall simulated ground subsidence and induced seismicity due to withdrawal of fluid from the $\mathrm{P}$ layer. We examine how the surface reservoir influences the occurrence of an earthquake in the $\mathrm{P}$ layer. Moreover, the $\mathrm{E}$ and H layers in Segall's (1985) model were 'fluidinfiltrated, impermeable', while in our case, they are dry and impermeable.

The main contribution of this paper, namely, analytical estimation of stress and pore pressure fields in the above NHCEM due to oscillatory and steady loads is placed in Appendix A because of its mathematical content. The sample results discussed in sections 3-7 enable us to interpret the observations of earthquakes under Lake Mead at epochs of low reservoir level (Roeloffs 1988). The earthquakes occurred on steeply dipping normal faults at $5000 \mathrm{~m}$ depth. We shall refer to these earthquakes as Lake Mead earthquakes (LMEQs).

\section{Preliminaries}

\subsection{Earth model: ONHCEM}

Properties of the different layers of the model shown in figure 1(a) are listed in table 1. Poroelastic properties of Ohio sandstone given by Wang (2000, table C1) have been adopted for the P layer. We will refer to this specific model as the Ohio NHCEM (ONHCEM).

\subsection{The reservoir model}

We consider a uniform circular reservoir with a radius of $4000 \mathrm{~m}$. Its water level oscillates 
Table 1. Properties of ONHCEM.

\begin{tabular}{lccc}
\hline Layer & Thickness $(\mathrm{m})$ & Elastic properties & Poroelastic properties \\
\hline $\mathrm{E}$ & 4950 & $\nu_{E}=0.18, G_{E}=6.8 \mathrm{GPa}$ & Nil \\
$\mathrm{P}$ & 100 & $\nu_{d P}=0.18, G_{P}=6.8 \mathrm{GPa}$ & $\nu_{u P}=0.28, \alpha_{P}=0.74$, \\
& & $c_{P}=3.9 \times 10^{-2} \mathrm{~m}^{2} / \mathrm{s}$ \\
$\mathrm{H}$ & 5050 to $+\infty$ & $\nu_{H}=0.18, G_{H}=6.8 \mathrm{GPa}$ & $\mathrm{Nil}$ \\
\hline
\end{tabular}

Table 2. Stresses and pore pressure at the point (3000 $\left.\mathrm{m}, 0^{\circ}, 5000 \mathrm{~m}\right)$ in the P layer.

\begin{tabular}{|c|c|c|c|}
\hline & \multirow{2}{*}{$\begin{array}{l}\text { Contribution due } \\
\text { to } H^{\prime}=1 \mathrm{~m} \\
(\mathrm{~Pa})\end{array}$} & \multicolumn{2}{|c|}{$\begin{array}{c}\text { Full poroelastic } \\
\text { contribution due to } h=1 \mathrm{~m}\end{array}$} \\
\hline & & $\begin{array}{l}\overline{\mathrm{Amp}} \\
(\mathrm{Pa})\end{array}$ & $\begin{array}{c}\text { Phase } \\
(0)\end{array}$ \\
\hline$\sigma_{z z P}$ & 3818 & 4609 & 0.05 \\
\hline$\tau_{r z P}$ & 1354 & 1354 & 0.0 \\
\hline$\sigma_{r r P}$ & 304 & 1083 & 0.16 \\
\hline$\sigma_{\theta \theta P}$ & -25 & 751 & 0.21 \\
\hline$p_{P}$ & 0 & 1063 & -179.8 \\
\hline
\end{tabular}

harmonically with an angular frequency $\omega$ of $2 \times$ $10^{-7}$ radians per second, corresponding to an year of 364.7 days approximately. Since values of $t$ between 0 and $\pi \times 10^{7} \mathrm{~s}$ could be required, we use, instead of time $t$, phase $\omega t$ of reservoir level expressed in degrees $\left(^{\circ}\right)$. Reservoir level corresponding to water depth $H^{\prime}-h$ at $\omega t=180^{\circ}$ will be referred hereafter as LRL (lowest reservoir level during routine annual operation). Similarly, reservoir level corresponding to water depth $H^{\prime}+h$ at $\omega t=0^{\circ}$ or $360^{\circ}$ will be referred to as HRL (highest reservoir level during routine annual operation).

\subsection{Reference axial plane RAP}

The origin $\mathrm{O}$ of the $(r, \theta, z)$ cylindrical coordinate system used in Appendix A (figure 1a) lies at the base of the circular reservoir and coincides with its center. The z-axis points down into the ONHCEM. The concept of a reference axial plane (RAP) defined by the $\mathrm{z}$-axis and the initial line of the $\theta$ coordinate is convenient.

Without loss of generality, the strike of every normal fault considered in the following sections is normal to the RAP. Then, the intersection of the fault and the RAP, shown schematically in figure 1(c), is a dip-parallel line of symmetry (LOS) in the fault. Maximum influence of the circular reservoir on a buried fault is along the latter's LOS.

\section{Reservoir influence at a point in the $\mathbf{P}$ layer}

The theory of Appendix A allows us to compute reservoir influence in terms of stress components $\sigma_{z z}, \sigma_{r r}, \sigma_{\theta \theta}, \tau_{r z}=\tau_{z r}$ and pore pressure $p$ at any point in the ONHCEM. The remaining two pairs of shear stress components are zero because of axial symmetry. We present in table 2, as an example, estimates of the stress components and pore pressure at $\left(3000 \mathrm{~m}, 0^{\circ}, 5000 \mathrm{~m}\right)$ in the $\mathrm{P}$ layer. The value of a stress component at such a point is the sum of: (1) a time independent elastic contribution due to $H^{\prime}$ (column 2 of table 2) and (2) an oscillatory porous-elastic contribution due to $h \cos (\omega t)$ (column 3). Pore pressure at the point arises due to $h \cos (\omega t)$ only. The total reservoir influence at the point $\left(3000 \mathrm{~m}, 0^{\circ}, 5000 \mathrm{~m}\right)$ is obtained by combining results from second and third columns of table 2 using specific values of $H^{\prime}$ and $h$. Thus, for example,

$$
\begin{aligned}
\sigma_{z z P}\left(3000 \mathrm{~m}, 0^{\circ}, 5000 \mathrm{~m}\right)= & H^{\prime}(3818)+h(4605) \\
& \times \cos \left(\omega t+0.2^{\circ}\right) \mathrm{Pa} .
\end{aligned}
$$

The small values of phases listed in the third column of table 2 indicate that stresses are very nearly in phase and the pore pressure is similarly in opposite phase to oscillating water level.

\section{Reservoir influence on an extended area of a fault in ONHCEM}

The reservoir influence on a fault in the ONHCEM will be in the form of normal stress $(\sigma)$ in $\mathrm{E}$ and $\mathrm{H}$ layers and as effective-normal stress $\left(\sigma^{\prime}=\sigma-\alpha p\right.$, see Appendix B) in the $\mathrm{P}$ layer. There will also be shear stress components $\tau_{d}$ and $\tau_{s}$ along dip and strike directions of the fault for points in every layer. These stress components may be computed for each point on a fault using such stress and pore pressure data as given in table 2 . The $3 \mathrm{D}$ formulas for transformation of stress components (e.g., Love 1944) are required. 


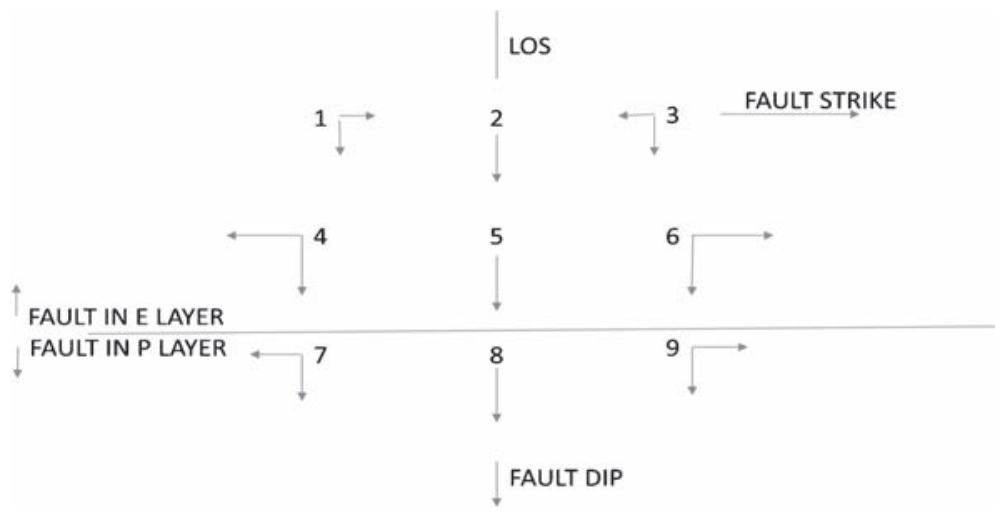

Figure 2. A schematic view of a dipping fault plane when we look down on it normally. See section 4 for full details. The arrows near the points 1 to 9 show dip and strike components of the reservoir induced shear stress along the fault. Exact values given in table 3(c and d) are shown here schematically. The rock in the hanging wall of the fault at a point will tend to move in the direction of an arrow under reservoir influence.

Table 3(a). Coordinates of points 1-9 shown schematically in figure 2.

\begin{tabular}{lll}
\hline $\mathbf{1}\left(6647 \mathrm{~m},-37.0^{\circ}, 1000 \mathrm{~m}\right)$ & $\mathbf{2}\left(5309 \mathrm{~m}, 0^{\circ}, 1000 \mathrm{~m}\right)$ & $\mathbf{3}\left(6647 \mathrm{~m}, 37.0^{\circ}, 1000 \mathrm{~m}\right)$ \\
$\mathbf{4}\left(5767 \mathrm{~m},-43.9^{\circ}, 3000 \mathrm{~m}\right)$ & $\mathbf{5}\left(4155 \mathrm{~m}, 0^{\circ}, 3000 \mathrm{~m}\right)$ & $\mathbf{6}\left(5767 \mathrm{~m}, 43.9^{\circ}, 3000 \mathrm{~m}\right)$ \\
$\mathbf{7}\left(5000 \mathrm{~m},-55.1^{\circ}, 5000 \mathrm{~m}\right)$ & $\mathbf{8}\left(3000 \mathrm{~m}, 0^{\circ}, 5000 \mathrm{~m}\right)$ & $\mathbf{9}\left(5000 \mathrm{~m}, 55.1^{\circ}, 5000 \mathrm{~m}\right)$ \\
\hline
\end{tabular}

Table 3(b). Values of $\sigma$ and $\sigma^{\prime}(M P a)$ at points $1-9$ of figure 2.

\begin{tabular}{lll}
\hline $\mathbf{1}(\sigma=0.049)$ & $\mathbf{2}(\sigma=0.172)$ & $\mathbf{3}(\sigma=0.049)$ \\
$\mathbf{4}(\sigma=0.185)$ & $\mathbf{5}(\sigma=0.386)$ & $\mathbf{6}(\sigma=0.185)$ \\
$\mathbf{7}\left(\sigma^{\prime}=0.153\right)$ & $\mathbf{8}\left(\sigma^{\prime}=0.252\right)$ & $\mathbf{9}\left(\sigma^{\prime}=0.153\right)$ \\
\hline
\end{tabular}

We show in figure 2 , a $3 \times 3$ grid of points on a $60^{\circ}$ fault in the $\mathrm{E}$ and $\mathrm{P}$ layers. The points, numbered 1-9, span an area of $8 \mathrm{~km}$ along fault strike and about $4.6 \mathrm{~km}$ along fault dip. Points 2,5 and 8 lie on the LOS of the fault. The remaining six points lie in symmetrical positions on either side of LOS. Two rows of points lie in the E layer and one row lies in the $\mathrm{P}$ layer. The reservoir is in the hanging wall of the fault as far as these points are concerned. The coordinates of the points are listed in table 3(a). For the sake of continuity in discussion, point 8 of the grid is also the point for which stresses and pore pressure are listed in table 2 .

We list in table 3(b, c and d), numerical values of resolved stress components acting on the fault at the nine grid points. Positive values of entries in these tables indicate respectively that $\sigma$ or $\sigma^{\prime}$ is compressive, $\tau_{d}$ promotes thrusting and $\tau_{s}$ promotes left-lateral strike-slip effect on the fault plane.

A schematic view of the shear stress components at the grid points is shown in figure 2. We learn from this figure and the tables that $\sigma^{\prime}$ or $\sigma$ and $\tau_{d}$ have maximum magnitudes and $\tau_{s}$ is zero along the LOS of the fault. This reservoir influence in terms of stresses on the dipping fault is the same regardless of whether the fault is dip-slip normal or dip-slip reverse/thrust, etc.
Table 3(c). Values of $\tau_{d}(M P a)$ at points 1-9 of figure 2.

\begin{tabular}{lll}
\hline $\mathbf{1}(+0.003)$ & $\mathbf{2}(-0.024)$ & $\mathbf{3}(+0.003)$ \\
$\mathbf{4}(-0.075)$ & $\mathbf{5}(-0.224)$ & $\mathbf{6}(-0.075)$ \\
$\mathbf{7}(-0.129)$ & $\mathbf{8}(-0.235)$ & $\mathbf{9}(-0.129)$ \\
\hline
\end{tabular}

Table 3(d). Values of $\tau_{s}(\mathrm{MPa})$ at points 1-9 of figure 2.

\begin{tabular}{lll}
\hline $\mathbf{1}(+0.023)$ & $\mathbf{2}(0.0)$ & $\mathbf{3}(-0.023)$ \\
$\mathbf{4}(-0.089)$ & $\mathbf{5}(0.0)$ & $\mathbf{6}(+0.089)$ \\
$\mathbf{7}(-0.088)$ & $\mathbf{8}(0.0)$ & $\mathbf{9}(+0.088)$ \\
\hline
\end{tabular}

\section{Review of reservoir-induced stability of normal faults}

Net earthquake-related influence on a fault is quantified using the concept of fault stability $S(\omega t)$. An earthquake will occur at a point on the fault near a reservoir at phase $\omega t$ if

$$
S(\omega t)=S_{T}(\omega t)+S_{R}(\omega t)=0 .
$$

Here, $S_{T}(\omega t)$ and $S_{R}(\omega t)$ are contributions to $S(\omega t)$ due to ambient tectonic and reservoir influences respectively. $S(\omega t)$ is positive at all times but decreases to zero at the time of the earthquake.

$S_{R}(\omega t)$ for a point on a pure dip-slip normal fault in the ONHCEM is defined by the following relations (e.g., after Roeloffs 1988),

$$
\begin{aligned}
S_{R}(\omega t) & =[\sigma(\omega t)-\alpha p(\omega t)] \tan \phi+\tau_{d}(\omega t) \\
& =\sigma^{\prime}(\omega t) \tan \phi+\tau_{d}(\omega t),
\end{aligned}
$$


at a point in the $\mathrm{P}$ layer;

$$
S_{R}(\omega t)=\sigma(\omega t) \tan \phi+\tau_{d}(\omega t)
$$

at a point in $\mathrm{E}$ or $\mathrm{H}$ layer.

The following expressions have been used by us for $\sigma$ and $\tau_{d}$.

$$
\begin{gathered}
\sigma=\sigma_{z z} \cos ^{2} \delta+\sigma_{r r} \sin ^{2} \delta+2 \tau_{r z} \cos \delta \sin \delta \\
\tau_{d}=\left(\sigma_{r r}-\sigma_{z z}\right) \sin \delta \cos \delta \pm \tau_{r z}\left(\cos ^{2} \delta-\sin ^{2} \delta\right) .
\end{gathered}
$$

The second expression is written for a normal fault dipping down from right to left in cross-section. The ' + ' or '-' sign is to be used according as the coordinates of the point on the fault are $\left(r, 0^{\circ}, z\right)$ or $\left(r, 180^{\circ}, z\right)$.

All these expressions are based on the assumptions that compressive stresses are positive and positive shear stress opposes slip on the normal fault. We assume a nominal value of $\tan \phi=0.6$ for fault friction coefficient. A positive value of $S_{R}(\omega t)$ implies stabilizing reservoir influence on normal faults considered here and vice versa.

\section{6. $S_{R}(\omega t)$ for two locations of a $60^{\circ}$ normal fault}

We consider reservoir influence on a $60^{\circ}$ normal fault passing through the point $\left(3000 \mathrm{~m}, 180^{\circ}\right.$, $5000 \mathrm{~m}$ ) in such a way that the reservoir is mostly on its footwall (e.g., Roeloffs 1988; Talwani 1997). Fault 1 in figure 1(b) is a schematic representation of this situation. The graph in figure 3(a) shows variation of $S_{R}(\omega t)$ at this point on this fault over one complete cycle of water level fluctuation. $S_{R}(\omega t)$ is positive and this normal fault is under a stabilizing reservoir influence throughout the year. In other words, the reservoir actually opposes the occurrence of an earthquake on the fault continuously. The earthquake is most likely at the point at LRL because the stabilizing reservoir influence is the weakest at that epoch. The earthquake will occur at a given epoch of LRL only if the destabilizing tectonic influence equals the stabilizing reservoir influence in magnitude at that epoch. We learn from figure $3(\mathrm{a})$ keeping table 2 in mind that fault stability increases and decreases in phase with reservoir level.

We note here, for comparison in section 8.5, that the computed numerical values of contributions to fault stability due to steady reservoir depth $H^{\prime}=110 \mathrm{~m}$ is $+3.21 \times 10^{-2} \mathrm{MPa}$, stabilizing. The corresponding value at LRL for $h=3 \mathrm{~m}$ is $-8.60 \times 10^{-4} \mathrm{MPa}$, destabilizing. The net stabilizing contribution at LRL is $+3.12 \times 10^{-2} \mathrm{MPa}$.

Figure 3(b) pertains to a $60^{\circ}$ normal fault passing through the point $\left(3000 \mathrm{~m}, 0^{\circ}, 5000 \mathrm{~m}\right)$. Schematically, this fault would lie to the right of
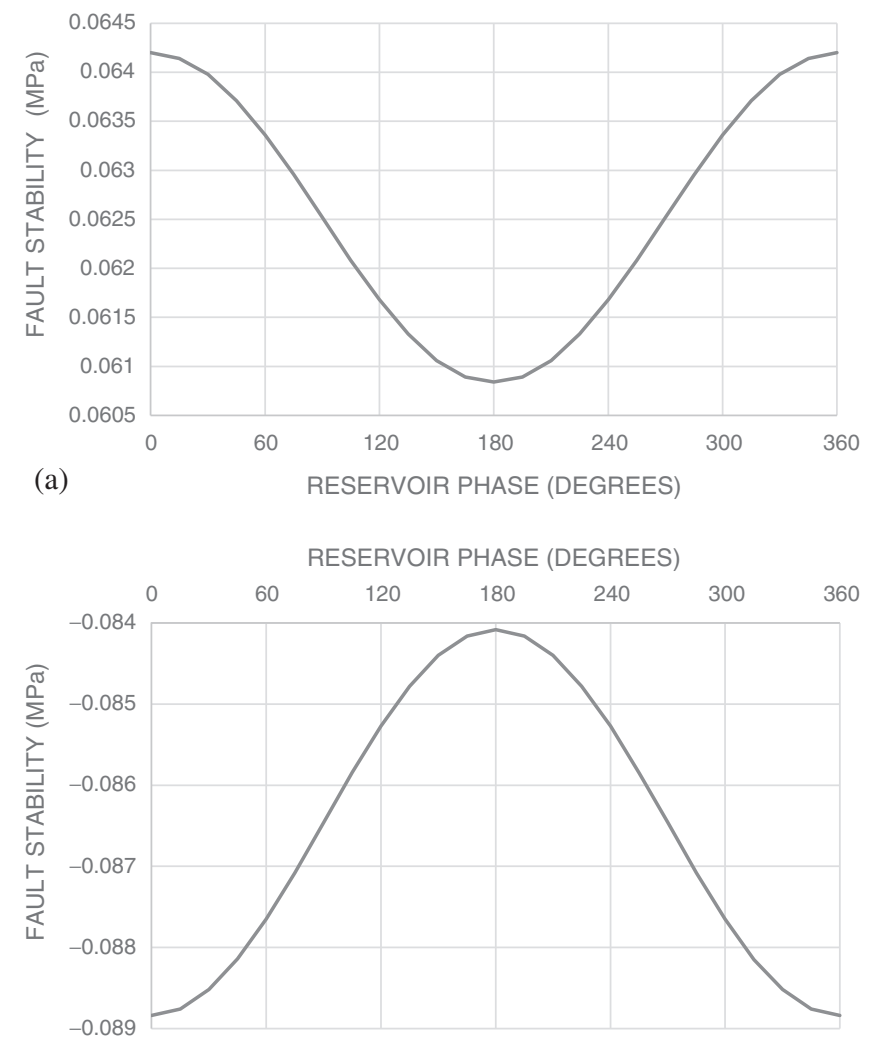

(b)

Figure 3. (a) Variation of reservoir induced stability $S_{R}(\omega t)$ of a $60^{\circ}$ normal fault for one annual harmonic reservoir cycle. Fault 1 of figure 1(b) represents this fault schematically in orientation and general location. The results are for the point $\left(3000 \mathrm{~m}, 180^{\circ}, 5000 \mathrm{~m}\right)$ on the fault in the $\mathrm{P}$ layer. The reservoir influence is stabilizing throughout the year. See section 6 of text. (b) $S_{R}(\omega t)$ for a fault described in third paragraph of section 6 . The destabilizing reservoir influence is maximum when $\omega t$ is $0^{\circ}$ and $360^{\circ}$ (i.e., HRL) and minimum when $\omega t$ is $180^{\circ}$ (i.e., LRL).

and parallel to Fault 2 of figure 1(b), so that the entire reservoir is in its hanging wall. Since $S_{R}(\omega t)$ is negative over the entire reservoir cycle, the fault is under a destabilizing reservoir influence throughout the year. The influence is most destabilizing at epochs of HRL ( $\omega t=0^{\circ}, 360^{\circ}$, etc.) and an earthquake is most likely at such epochs. The earthquake will occur if the magnitudes of destabilizing reservoir influence at an epoch of HRL and stabilizing tectonic influence at that epoch are equal. The reservoir influence actively promotes the occurrence of the earthquake in this case. We emphasize that in this case the destabilizing reservoir influence increases as the water level rises in the reservoir and vice versa.

\section{Further results on variations in $S_{R}(\omega t)$ for normal faults}

Figure 4(a) shows magnitude of $S_{R}$ at LRL at several points on the Fault 1 of figure 1(b). The 


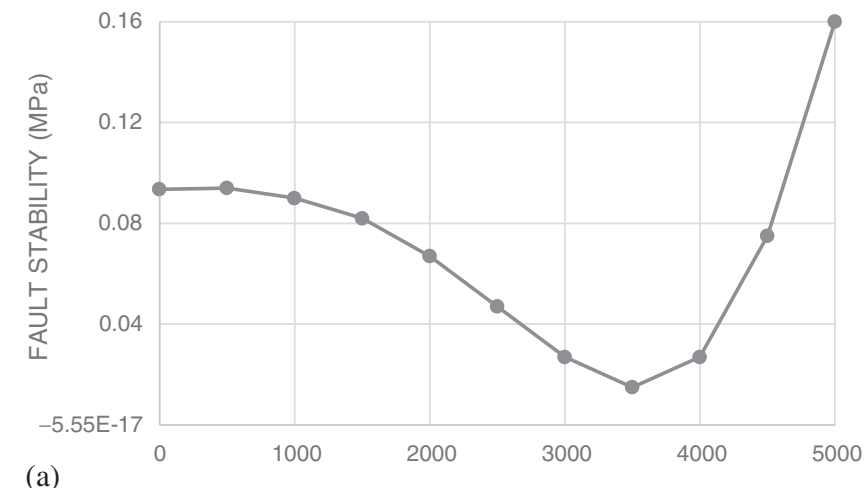

(a)

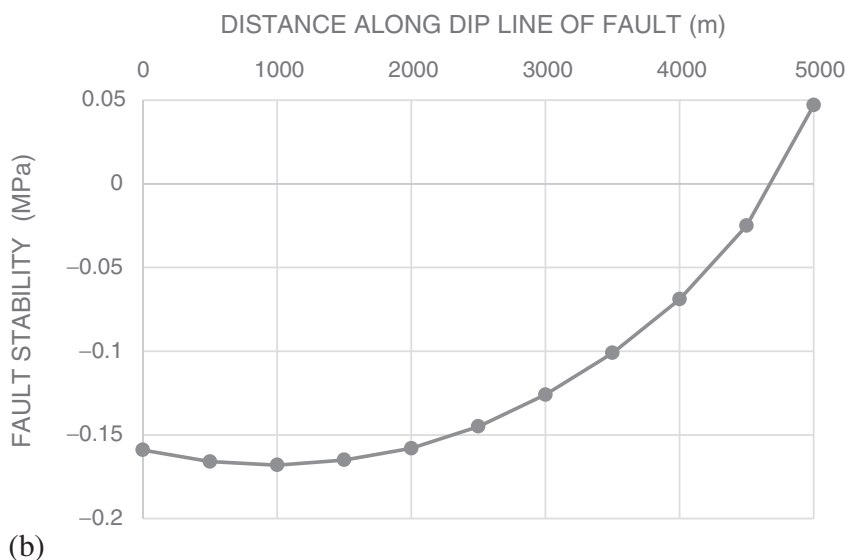

Figure 4. (a) Variation of $S_{R}$ at LRL with distance along a fault, which is similar to Fault 1 of figure 1(b). The distance is measured up dip from the point with coordinates $\left(3500 \mathrm{~m}, 180^{\circ}, 5000 \mathrm{~m}\right)$. The reservoir influence is stabilizing at all points considered. (b) Variation of $S_{R}$ at LRL with distance along a fault which is similar to Fault 2 of figure $1(\mathrm{~b})$. The distance is measured up dip from the point with coordinates $\left(500 \mathrm{~m}, 0^{\circ}, 5000 \mathrm{~m}\right)$. The reservoir influence is destabilizing at most points considered, but stabilizing at the right most point. Both faults dip at $60^{\circ}$.

origin of the horizontal axis corresponds to point $\left(3500 \mathrm{~m}, 180^{\circ}, 5000 \mathrm{~m}\right)$ and the dip of the fault is $60^{\circ}$. We learn that the reservoir influence is stabilizing at all points considered. Figure 4(b) is similar but for Fault 2 of figure 1(b). The origin of the horizontal axis corresponds to point $\left(500 \mathrm{~m}, 0^{\circ}\right.$, $5000 \mathrm{~m}$ ) and the dip of the fault is $60^{\circ}$ again. We learn that the reservoir influence is destabilizing at most but not all points are considered.

Figure 5(a) is the visualization of a $60^{\circ}$ normal fault dipping to the left at different horizontal positions in the $\mathrm{P}$ layer under the reservoir. The phrase 'reservoir mostly on the footwall of the normal fault' applies fairly for fault positions at the extreme left of the figure. Figure 5(b) depicts computed values of reservoir induced stabilizing or destabilizing influence on the fault. All calculations are for LRL. Points marked $-4000 \mathrm{~m}$ and $4000 \mathrm{~m}$ on the horizontal axis have coordinates $\left(4000 \mathrm{~m}, 180^{\circ}, 5000 \mathrm{~m}\right)$ and $\left(4000 \mathrm{~m}, 0^{\circ}, 5000 \mathrm{~m}\right)$ respectively. Earthquakes at LRL on $60^{\circ}$ normal
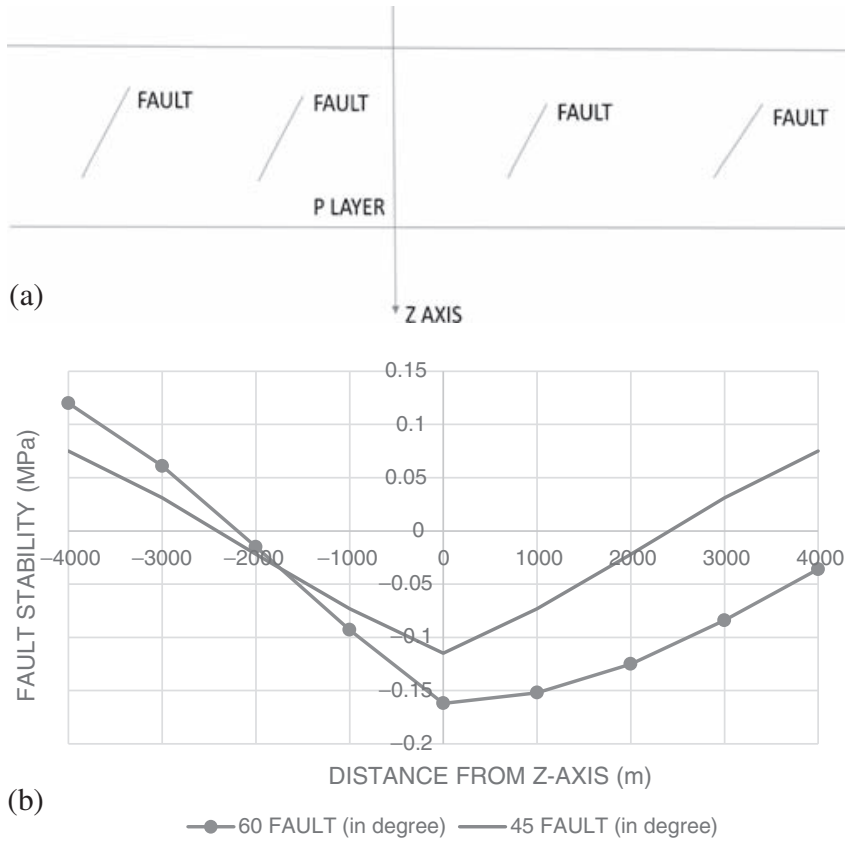

Figure 5. (a) Schematic representation of the same $60^{\circ}$ normal fault at several possible horizontal positions in the $\mathrm{P}$ layer. (b) Variation of $S_{R}$ at LRL with horizontal position of the fault. See sections 7 and 8.2 for details. The point marked $-4000 \mathrm{~m}$ on the horizontal axis has coordinates $\left(4000 \mathrm{~m}, 180^{\circ}, 5000 \mathrm{~m}\right)$. A similar curve for $45^{\circ}$ normal fault is included (see section 8.2).

faults will be favoured for positions approximately in the range $\left(4000 \mathrm{~m}>r>2200 \mathrm{~m}, 180^{\circ}, 5000 \mathrm{~m}\right)$.

Results for a fault dipping at $45^{\circ}$ to the left are included in figure 5(b) (see section 8.2). It emerges that earthquakes at LRL will be favoured on this fault for positions between $(2300 \mathrm{~m}<r<4000 \mathrm{~m}$, $0^{\circ}, 5000 \mathrm{~m}$ ) also. The reservoir is on the hanging wall of the fault at these positions. We trace this result to the specific nature of the dependence of $\sigma$ and $\tau_{d}$ on fault $\operatorname{dip} \delta$ (see sections 5 and 8.2).

\section{Discussion}

\subsection{About NHCEM}

The theory of Appendix A deals with a three-layered NHCEM. Additional horizontal elastic layers may be included in the earth model without conceptual change in the theory. Similarly, more poroelastic layers may be included also. But each poroelastic layer must be sandwiched between two impermeable elastic layers. This ensures that water does not flow in or out of the poroelastic layer perpendicularly across its upper and lower boundaries.

\subsection{Possibility of normal fault earthquakes in ONHCEM at low reservoir levels}

Having adopted the value of $4000 \mathrm{~m}$ for the radius of the uniform circular model of Lake Mead, we 
have confined our attention in the reported results to points whose $r$-coordinates have values less than $4000 \mathrm{~m}$ because we were concerned about rationalization of 'normal fault earthquakes under Lake Mead'.

Figures 3(a), 5(b) and the discussion of section 6 indicate that, during steady state reservoir operation, at least at some points under the reservoir, earthquakes can occur at LRL on a $60^{\circ}$ normal fault in the $\mathrm{P}$ layer of the ONHCEM. The reservoir should be located mostly on the footwall of the normal fault passing through such a point. For the sequence of $60^{\circ}$ normal faults shown schematically in figure 5(a), the results shown in figure 5(b) indicate that faults near the left end of the depicted horizontal axis would be suitable hosts for such earthquakes.

Results for normal faults dipping at $45^{\circ}$ are included in figure 5(b) because Rogers and Lee (1976) noted from the analysis of seismological data that LMEQs could have occurred on such faults. We learn that earthquakes can occur at epochs of LRL on $45^{\circ}$ normal faults in ONHCEM, even when the reservoir is on the hanging wall of the fault.

Finally, it is expected from the theory of section 5 , and may be seen from figure $5(\mathrm{~b})$ that the nature of reservoir influence on normal faults passing through the same subsurface point and having the same dip direction varies significantly with the amount of fault dip. For example, at the point with coordinates $\left(3000 \mathrm{~m}, 0^{\circ}, 5000 \mathrm{~m}\right)$, the influence is destabilizing when $\delta=60^{\circ}$ and stabilizing when $\delta=45^{\circ}$.

The influence of a circular reservoir on other types of faults, such as reverse/thrust dip slip, vertical strike slip, or general oblique slip on dipping faults, in the $\mathrm{P}$ layer of the ONHCEM may be deduced similarly.

\subsection{Comparison of normal fault-related results for ONHCEM with published results for LMEQs}

LMEQs started occurring several years after the impoundment of Lake Mead was initiated. But they were observed for more than two decades thereafter (Roeloffs 1988). Roeloffs (1988) considered the long history of LMEQs as a steady state effect of sustained reservoir operation. She analyzed these observations with a FHCEM, comprising a single poroelastic layer of semi-infinite thickness. She inferred that at the focus of such an earthquake in FHCEM, the reservoir influence due to the mean water depth should be stabilizing and that due to water oscillations should be destabilizing. The numerical values of fault stability quoted in section 6 for ONHCEM display these features precisely. In other words, the occurrence of LMEQs under sustained, periodic operation of Lake Mead can be explained using the ONHCEM also. This conforms to the general geophysical experience that more than one earth model may explain all, or a fraction, of a given set of geophysical observations.

Talwani and Acree (1985) estimated hydraulic diffusivity $c$ 'within an order of magnitude of $5 \mathrm{~m}^{2} \mathrm{~s}^{-1}$, under reservoirs exhibiting induced seismicity. According to Roeloffs (1988), explanation of LMEQs using the FHCEM requires that its material should have low value of $c$. Her estimate for the Lake Mead region is between 0.01 and $0.26 \mathrm{~m}^{2} \mathrm{~s}^{-1}$. The value of $c=0.04 \mathrm{~m}^{2} \mathrm{~s}^{-1}$ used for ONHCEM was fixed when we arbitrarily adopted Ohio sandstone as the material of the $\mathrm{P}$ layer.

\section{Conclusion}

Investigations of post-impoundment earthquakes near a new man-made reservoir should be initiated keeping in mind that, depending on local geological conditions, water from the reservoir may or may not seep to earthquake depths. Chances of the second possibility increase with increase in focal depths of earthquakes. We may assess the situation through site investigations, simulations, or a combination of both. The expressions derived here for stresses and pore pressure may be used with the simulation approach. On the basis of our analysis of some Lake Mead earthquakes, we conclude that results from the proposed three-layered, no-hydraulic-connection earth model may be combined with those from the widely-used, singlelayered, full-hydraulic-connection earth model for comprehensive interpretation of observations.

\section{Acknowledgements}

We appreciate the constructive comments of the two reviewers. We acknowledge, in particular, the suggestion of one reviewer to look at Talwani (1997) also. This simplified the analysis of LMEQs using ONHCEM significantly.

\section{Appendix A}

\section{Response of NHCEM to a uniform circular load on its top surface}

We solve the axially symmetric problem of determining the influence of a uniform circular load on a NHCEM. The basic theoretical framework for axial symmetry in a poroelastic medium is provided by Wang (2000, sections 9.1 and 9.6). It is adopted here with minor adjustments for $\cos (\omega t)$ time variations. The theoretical framework for the $\mathrm{E}$ and $\mathrm{H}$ layers is obtained by suitable simplification. The dependent variables are treated as 
complex-valued quantities in sections A1 to A5 dealing with $h \cos (\omega t)$ component of water depth. The response of NHCEM to the $H^{\prime}$ component is considered in section A6.

\section{A1. Mathematical statement of the problem}

\section{A1.1 Constitutive relations}

The following constitutive equations hold for the $\mathrm{P}$ layer (Wang 2000, equations 2.50, 2.53 and 2.68) in the axially symmetric case.

$$
\begin{gathered}
\sigma_{z z P}=2 G_{P} \frac{\partial u_{z P}}{\partial z}+\frac{2 G_{P} \nu_{u P}}{1-2 \nu_{u P}} \epsilon_{P}-B_{P} K_{u P} \zeta_{P} \\
\tau_{r z P}=G_{P}\left(\frac{\partial u_{z P}}{\partial r}+\frac{\partial u_{r P}}{\partial z}\right) \\
p_{P}=-B_{P} K_{u P} \epsilon_{P}+\frac{B_{P} K_{u P}}{\alpha_{P}} \zeta_{P} \\
\sigma_{z z P}^{\prime}=\sigma_{z z P}+\alpha_{P} p_{P}
\end{gathered}
$$

The constitutive equations for the $\mathrm{E}$ and $\mathrm{H}$ layers are, with $j=\mathrm{E}, \mathrm{H}$ :

$$
\begin{aligned}
\sigma_{z z j} & =2 G_{j} \frac{\partial u_{z j}}{\partial z}+\frac{2 G_{j} \nu_{j}}{1-2 \nu_{j}} \epsilon_{j} \\
\tau_{r z j} & =G_{j}\left(\frac{\partial u_{z j}}{\partial r}+\frac{\partial u_{r j}}{\partial z}\right) .
\end{aligned}
$$

\section{A1.2 Field equations}

The following field equations hold for the $\mathrm{P}$ layer (Wang 2000, equations 4.25, 4.67, and 9.8).

$$
\begin{gathered}
\nabla^{2} \zeta_{P}=\frac{1}{c_{P}} \frac{\partial \zeta_{P}}{\partial t}, \\
\nabla^{2} \epsilon_{P}=\gamma_{P} \nabla^{2} \zeta_{P}, \\
G_{P}\left(\frac{\partial^{2} u_{r P}}{\partial r^{2}}+\frac{1}{r} \frac{\partial u_{r P}}{\partial r}-\frac{u_{r P}}{r^{2}}+\frac{\partial^{2} u_{r P}}{\partial z^{2}}\right) \\
+\frac{G_{p}}{1-2 \nu_{u P}} \frac{\partial \epsilon_{p}}{\partial r}-B_{P} K_{u P} \frac{\partial \zeta_{P}}{\partial r}=0, \\
G_{P}\left(\frac{\partial^{2} u_{z P}}{\partial r^{2}}+\frac{1}{r} \frac{\partial u_{z P}}{\partial r}+\frac{\partial^{2} u_{z P}}{\partial z^{2}}\right) \\
+\frac{G_{p}}{1-2 \nu_{u P}} \frac{\partial \epsilon_{p}}{\partial z}-B_{P} K_{u P} \frac{\partial \zeta_{P}}{\partial z}=0 .
\end{gathered}
$$

The simpler field equations for the $\mathrm{E}$ and $\mathrm{H}$ layers are, again with $j=\mathrm{E}, \mathrm{H}$ :

$$
\nabla^{2} \epsilon_{j}=0,
$$

$$
\left(\frac{\partial^{2} u_{r j}}{\partial r^{2}}+\frac{1}{r} \frac{\partial u_{r j}}{\partial r}-\frac{u_{r j}}{r^{2}}+\frac{\partial^{2} u_{r j}}{\partial z^{2}}\right)+\frac{1}{1-2 \nu_{j}} \frac{\partial \epsilon_{j}}{\partial r}=0,
$$

$$
\left(\frac{\partial^{2} u_{z j}}{\partial r^{2}}+\frac{1}{r} \frac{\partial u_{z j}}{\partial r}+\frac{\partial^{2} u_{z j}}{\partial z^{2}}\right)+\frac{1}{1-2 \nu_{j}} \frac{\partial \epsilon_{j}}{\partial z}=0 .
$$

\section{A1.3 Boundary conditions}

The following four sets of boundary conditions hold for all $r$ and $t$.

(1) As $z \rightarrow \infty u_{r H}, u_{z H}, \tau_{r z H}, \sigma_{z z H} \rightarrow 0$.

(2) At the lower boundary of the P layer

$$
\begin{aligned}
u_{r H} & =u_{r P}, \quad u_{z H}=u_{z P}, \\
\tau_{r z H} & =\tau_{r z P}, \quad \sigma_{z z H}=\sigma_{z z P}^{\prime}, \\
\frac{\partial p_{P}}{\partial z} & =0 .
\end{aligned}
$$

(3) At the upper boundary of the P layer

$$
\begin{aligned}
u_{r P} & =u_{r E}, \quad u_{z P}=u_{z E}, \\
\tau_{r z P} & =\tau_{r z E}, \quad \sigma_{z z P}^{\prime}=\sigma_{z z E}, \\
\frac{\partial p_{P}}{\partial z} & =0 .
\end{aligned}
$$

(4) At the top boundary of the E layer

$$
\tau_{r z E}=0,
$$

and

$$
\sigma_{z z E}= \begin{cases}\operatorname{Re}\left[-\rho g h e^{s t}\right], & r \leq r_{R}, \\ 0, & r>r_{R} .\end{cases}
$$

The Hankel transform of $\sigma_{z z E}$ (Sneddon 1951; Singh et al. 2009) is:

$$
\bar{\sigma}_{z z E}^{0}=\frac{-\rho g h e^{s t} r_{R} J_{1}\left(k r_{R}\right)}{k} .
$$

The inverse Hankel transform is:

$$
\sigma_{z z E}=-\rho g h e^{s t} \int_{0}^{\infty}\left(\frac{r_{R}}{k}\right) J_{1}\left(r_{R} k\right) J_{0}(r k) k d k .
$$

\section{A1.4 Problem solved}

We discuss in sections A2-A4 evaluation of displacement components $u_{r}$ and $u_{z}$, and stress components $\sigma_{z z}$ and $\tau_{r z}$, in $\mathrm{E}, \mathrm{P}$ and $\mathrm{H}$ layers and pore pressure $\mathrm{p}$ in the $\mathrm{P}$ layer. We evaluate stress component $\sigma_{r r}$ in section A5.

\section{A2. Displacements, stresses and pore pressure in $\mathbf{E}, \mathbf{P}$ and $\mathrm{H}$ layers}

\section{A2.1 The P layer}

The following equations involving six unknown constants $A_{P}-F_{P}$ are based on Wang (2000, 
equations $9.42, \quad 9.46,9.47,9.48,9.50$ and $2.68)$.

$$
\begin{aligned}
u_{r P}(r, z, t, s)= & e^{s t} \int_{0}^{\infty}\left[F_{P} e^{-k z}+E_{P} e^{k z}\right. \\
& +b_{1 u P}\left(-D_{P} e^{-k z}+C_{P} e^{k z}\right) \\
& \left.-\frac{c k \gamma_{P}}{s}\left(A_{P} e^{m z}+B_{P} e^{-m z}\right)\right] \\
& \times k J_{1}(k r) d k
\end{aligned}
$$

$$
\begin{aligned}
u_{z P}(r, z, t, s)= & e^{s t} \int_{0}^{\infty}\left[F_{P} e^{-k z}-E_{P} e^{k z}\right. \\
& -\left(b_{1 u P} z+\frac{b_{2 u P}}{k}\right) D_{P} e^{-k z} \\
& -\left(b_{1 u P} z-\frac{b_{2 u P}}{k}\right) C_{P} e^{k z} \\
& \left.+\frac{c m \gamma_{P}}{s}\left(A_{P} e^{m z}-B_{P} e^{-m z}\right)\right] \\
& \times k J_{0}(k r) d k,
\end{aligned}
$$

$$
\begin{aligned}
\tau_{r z P}(r, z, t, s)= & 2 G_{P} e^{s t} \int_{0}^{\infty}\left[-F_{P} e^{-k z}+E_{P} e^{k z}\right. \\
& +\left(b_{1 u P} k z+0.5\right) D_{P} e^{-k z} \\
& +\left(b_{1 u P} k z-0.5\right) C_{P} e^{k z} \\
& \left.-\frac{c k m \gamma_{P}}{s}\left(A_{P} e^{m z}-B_{P} e^{-m z}\right)\right] \\
& \times k J_{1}(k r) d k
\end{aligned}
$$

$$
\begin{aligned}
\sigma_{z z P}^{\prime}(r, z, t, s)= & \sigma_{z z P}(r, z, t, s)+\alpha_{P} p_{P}(r, z, t, s) \\
= & 2 G_{P} e^{s t} \int_{0}^{\infty}\left[-F_{P} e^{-k z}-E_{P} e^{k z}\right. \\
& +\left(b_{1 u P} k z+b_{4 d P}\right) D_{P} e^{-k z} \\
& -\left(b_{1 u P} k z-b_{4 d P}\right) C_{P} e^{k z} \\
& +\left(\frac{c k^{2}}{s}+b_{4 d P}\right) \\
& \left.\times \gamma_{P}\left(A_{P} e^{m z}+B_{P} e^{-m z}\right)\right] \\
& \times k J_{0}(k r) d k
\end{aligned}
$$

$$
\begin{aligned}
\sigma_{z z}(r, z, t, s)= & 2 G_{P} e^{s t} \int_{0}^{\infty}\left[-F_{P} e^{-k z}-E_{P} e^{k z}\right. \\
& +\left(b_{1 u P} k z+b_{4 u P}\right) D_{P} e^{-k z} \\
& -\left(b_{1 u P} k z-b_{4 u P}\right) C_{P} e^{k z} \\
& \left.+\frac{c k^{2} \gamma_{P}}{s}\left(A_{P} e^{m z}+B_{P} e^{-m z}\right)\right] \\
& \times k J_{0}(k r) d k
\end{aligned}
$$

$$
\begin{gathered}
p_{P}(r, z, t, s)=2 G_{P} e^{s t} \int_{0}^{\infty}\left[-\gamma_{P} b_{4 u P}\left(D_{P} e^{-k z}+C_{P} e^{k z}\right)\right. \\
\left.\quad+\gamma_{P} b_{5 P}\left(A_{P} e^{m z}+B_{P} e^{-m z}\right)\right] k J_{0}(k r) d k .
\end{gathered}
$$

Equation $(14 \mathrm{~d})$ based on $(14 \mathrm{e}-\mathrm{f})$ is written after simplification.

\section{A2.1.1 Estimate of $A_{p}$ and $B_{p}$}

We use the two boundary conditions relating to the pore pressure gradient (see equations 2 and 3 ) to evaluate $A_{P}$ and $B_{P}$ in terms of $C_{P}$ and $D_{P}$. Thus, the term $\gamma_{P}\left(A_{P} e^{m z} \pm B_{P} e^{-m z}\right)$ appearing repeatedly in equation (14a-f) take the following forms.

$$
\gamma_{P}\left(A_{P} e^{m z} \pm B_{P} e^{-m z}\right)=\alpha_{D \pm} D_{P}+\alpha_{C \pm} C_{P} .
$$

Here,

$$
\begin{aligned}
\alpha_{D \pm} & =q\left(e^{m d_{P}+m z}-e^{k d_{P}+m z}\right) \pm q\left(e^{-m d_{P}-m z}-e^{k d_{P}-m z}\right), \\
\alpha_{C \pm} & =q\left(e^{-k d_{P}+m z}-e^{m d_{P}+m z}\right) \\
& \pm q\left(e^{-k d_{P}-m z}-e^{-m d_{P}-m z}\right), \\
q & =\frac{\gamma_{P} b_{4 u P} k}{b_{5 P}\left(e^{-m d_{P}}-e^{m d_{P}}\right)} .
\end{aligned}
$$

\section{A2.1.2 Revised expressions for P layer}

Equations (14a-f) may be rewritten now in terms of four unknown constants.

$$
\begin{aligned}
u_{r P}(r, z, t, s)= & e^{s t} \int_{0}^{\infty}\left[F_{P} e^{-k z}+E_{P} e^{k z}\right. \\
& +\left(-b_{1 u P} z-\frac{c k}{s} \alpha_{D+}\right) D_{P} e^{-k z} \\
& \left.+\left(b_{1 u P} z-\frac{c k}{s} \alpha_{C+}\right) C_{P} e^{k z}\right] \\
& \times k J_{1}(k r) d k
\end{aligned}
$$

$$
\begin{aligned}
u_{z P}(r, z, t, s)=e^{s t} \int_{0}^{\infty}\left[F_{P} e^{-k z}-E_{P} e^{k z}\right. \\
+\left(-b_{1 u P} z-\frac{b_{2 u P}}{k}+\frac{c m}{s} \alpha_{D-}\right) D_{P} e^{-k z} \\
\left.\quad-\left(-b_{1 u P} z+\frac{b_{2 u P}}{k}+\frac{c m}{s} \alpha_{C-}\right) C_{P} e^{k z}\right] \\
\quad \times k J_{0}(k r) d k
\end{aligned}
$$




$$
\begin{aligned}
\tau_{r z P}(r, & z, t, s)=2 G_{P} e^{s t} \int_{0}^{\infty}\left[-F_{P} e^{-k z}+E_{P} e^{k z}\right. \\
& +\left(b_{1 u P} k z+0.5-\frac{c k m}{s} \alpha_{D-}\right) D_{P} e^{-k z} \\
& \left.+\left(b_{1 u P} k z-0.5-\frac{c k m}{s} \alpha_{C-}\right) C_{P} e^{k z}\right] \\
& \times k J_{1}(k r) d k
\end{aligned}
$$$$
\sigma_{z z P}^{\prime}(r, z, t, s)=2 G_{P} e^{s t} \int_{0}^{\infty}\left[-F_{P} e^{-k z}-E_{P} e^{k z}\right.
$$$$
+\left\{b_{1 u P} k z+b_{4 d P}+\left(\frac{c k^{2}}{s}+b_{4 d P}\right) \alpha_{D+}\right\} D_{P} e^{-k z}
$$$$
\left.+\left\{-b_{1 u P} k z+b_{4 d P}+\left(\frac{c k^{2}}{s}+b_{4 d P}\right) \alpha_{C+}\right\} C_{P} e^{k z}\right]
$$$$
\times k J_{0}(k r) d k,
$$

$$
\begin{aligned}
\sigma_{z z}( & r, z, t, s)=2 G_{P} e^{s t} \int_{0}^{\infty}\left[-F_{P} e^{-k z}-E_{P} e^{k z}\right. \\
& +\left(b_{1 u P} k z+b_{4 u P}+\frac{c k^{2}}{s} \alpha_{D+}\right) D_{P} e^{-k z} \\
& \left.+\left(-b_{1 u P} k z+b_{4 u P}+\frac{c k^{2}}{s} \alpha_{C+}\right) C_{P} e^{k z}\right] \\
& \times k J_{0}(k r) d k,
\end{aligned}
$$

$$
\begin{aligned}
p_{P}(r, z, t, s)= & 2 G_{P} e^{s t} \int_{0}^{\infty} \\
& \times\left[\left(-\gamma_{P} b_{4 u P}+b_{5 P} \alpha_{D+}\right) D_{P} e^{-k z}\right. \\
& \left.+\left(-\gamma_{P} b_{4 u P}+b_{5 P} \alpha_{C+}\right) C_{P} e^{k z}\right] \\
& \times k J_{0}(k r) d k .
\end{aligned}
$$

\section{A2.2 The E layer}

The corresponding expressions for the E layer are:

$$
\begin{aligned}
u_{r E}(r, z, t, s)= & e^{s t} \int_{0}^{\infty}\left[F_{E} e^{-k z}+E_{E} e^{k z}\right. \\
& +b_{1 E}\left(-D_{E} e^{-k z}+C_{E} e^{k z}\right] \\
& \times k J_{1}(k r) d k, \\
u_{z E}(r, z, t, s)= & e^{s t} \int_{0}^{\infty}\left[F_{E} e^{-k z}-E_{E} e^{k z}\right. \\
& -\left(b_{1 E} z+\frac{b_{2 E}}{k}\right) D_{E} e^{-k z} \\
& \left.-\left(b_{1 E} z-\frac{b_{2 E}}{k}\right) C_{E} e^{k z}\right] \\
& \times k J_{0}(k r) d k,
\end{aligned}
$$

$$
\begin{aligned}
\tau_{r z E}(r, z, t, s)= & 2 G_{E} e^{s t} \int_{0}^{\infty}\left[-F_{E} e^{-k z}+E_{E} e^{k z}\right. \\
& +\left(b_{1 E} k z+0.5\right) D_{E} e^{-k z} \\
& \left.+\left(b_{1 E} k z-0.5\right) C_{E} e^{k z}\right] \\
& \times k J_{1}(k r) d k \\
\sigma_{z z E}(r, z, t, s)= & 2 G_{E} e^{s t} \int_{0}^{\infty}\left[-F_{E} e^{-k z}-E_{E} e^{k z}\right. \\
& +\left(b_{1 E} k z+b_{4 E}\right) D_{E} e^{-k z} \\
& \left.-\left(b_{1 E} k z-b_{4 E}\right) C_{E} e^{k z}\right] \\
& \times k J_{0}(k r) d k .
\end{aligned}
$$

\section{A2.3 The H layer}

Finally, similar expressions for the $\mathrm{H}$ layer:

$$
\begin{aligned}
u_{r H}(r, z, t, s)= & e^{s t} \int_{0}^{\infty}\left[F_{H} e^{-k z}+E_{H} e^{k z}\right. \\
& \left.+b_{1 H}\left(-D_{H} e^{-k z}+C_{H} e^{k z}\right)\right] \\
& \times k J_{1}(k r) d k \\
u_{z H}(r, z, t, s)= & e^{s t} \int_{0}^{\infty}\left[F_{H} e^{-k z}-E_{H} e^{k z}\right. \\
& -\left(b_{1 H} z+\frac{b_{2 H}}{k}\right) D_{B} e^{-k z} \\
& \left.-\left(b_{1 H} z-\frac{b_{2 H}}{k}\right) C_{H} e^{k z}\right] \\
& \times k J_{0}(k r) d k,
\end{aligned}
$$

$$
\begin{aligned}
\tau_{r z H}(r, z, t, s)= & 2 G_{H} e^{s t} \int_{0}^{\infty}\left[-F_{H} e^{-k z}+E_{H} e^{k z}\right. \\
& +\left(b_{1 H} k z+0.5\right) D_{H} e^{-k z} \\
& \left.+\left(b_{1 H} k z-0.5\right) C_{H} e^{k z}\right] \\
& \times k J_{1}(k r) d k, \\
\sigma_{z z H}(r, z, t, s)= & 2 G_{H} e^{s t} \int_{0}^{\infty}\left[-F_{H} e^{-k z}-E_{H} e^{k z}\right. \\
& +\left(b_{1 H} k z+b_{4 H}\right) D_{H} e^{-k z} \\
& \left.-\left(b_{1 H} k z-b_{4 H}\right) C_{H} e^{k z}\right] \\
& \times k J_{0}(k r) d k .
\end{aligned}
$$

The boundary conditions in equation (1) of A1.3 imply that $C_{H}=E_{H}=0$. Equations (18a-d) thus involve only $D_{H}$ and $F_{H}$. 


\section{A3. Determination of the remaining unknown constants}

\section{A3.1 Expressions in matrix form}

We switch to the Hankel transform domain. Equations $(16 \mathrm{a}-\mathrm{d}),(17 \mathrm{a}-\mathrm{d})$ and $(18 \mathrm{a}-\mathrm{d})$ are pertinent. Let

$$
\begin{gathered}
{\left[\bar{u}_{r j}^{1}, \bar{u}_{z j}^{0}, \bar{\tau}_{r z j}^{1}, \bar{\sigma}_{z z j}^{0}\right]^{T}(k, z, t, s)} \\
=\left[\bar{u}_{r j}^{1}(k, z, t, s), \bar{u}_{z j}^{0}(k, z, t, s), \bar{\tau}_{r z j}^{1}(k, z, t, s),\right. \\
\left.\quad \bar{\sigma}_{z z j}^{0}(k, z, t, s)\right]^{T} .
\end{gathered}
$$
we have

Then, with subscript $j=E, P$ and $H$ in turn,

$$
\begin{aligned}
& {\left[\bar{u}_{r E}^{1}, \bar{u}_{z E}^{0}, \bar{\tau}_{r z E}^{1}, \bar{\sigma}_{z z E}^{0}\right]^{T}(k, z, t, s)} \\
& \quad=e^{s t} \mathbf{Z}_{E}(k, z, s) \cdot\left[F_{E}, E_{E}, D_{E}, C_{E}\right]^{T} \\
& \quad\left[\bar{u}_{r P}^{1}, \bar{u}_{z P}^{0}, \bar{\tau}_{r z P}^{1}, \bar{\sigma}_{z z P}^{\prime 0}\right]^{T}(k, z, t, s) \\
& \quad=e^{s t} \mathbf{Z}_{P}(k, z, s) \cdot\left[F_{P}, E_{P}, D_{P}, C_{P}\right]^{T} \\
& {\left[\bar{u}_{r H}^{1}, \bar{u}_{z H}^{0}, \bar{\tau}_{r z H}^{1}, \bar{\sigma}_{z z H}^{0}\right]^{T}(k, z, t, s)} \\
& \quad=e^{s t} \mathbf{Z}_{H}(k, z, s) \cdot\left[F_{H}, E_{H}, D_{H}, C_{H}\right]^{T} .
\end{aligned}
$$

$\mathbf{Z}_{E}(k, z, s), \mathbf{Z}_{P}(k, z, s)$, and $\mathbf{Z}_{H}(k, z, s)$ are $4 \times 4$ matrices of coefficients of the constants in equations $(17 \mathrm{a}-\mathrm{d}),(16 \mathrm{a}-\mathrm{d})$ and $(18 \mathrm{a}-\mathrm{d})$ respectively.

\section{A3.2 Evaluation of unknown constants}

We follow Singh and Rani (2006) at this stage, and note that the values of variables at the top of $\mathrm{E}$ layer can be expressed in terms of arbitrary constants related to $\mathrm{H}$ layer through the following matrix relations by using the boundary conditions in equations (1), (2) and (3) of A1.3.

$$
\begin{gathered}
{\left[\bar{u}_{r E T}^{1}, \bar{u}_{z E T}^{0}, \bar{\tau}_{r z E T}^{1}, \bar{\sigma}_{z z E T}^{0}\right]^{T}(k, 0, t, s)} \\
=e^{s t} \mathbf{J}(k, s) \cdot\left[F_{H}, 0, D_{H}, 0\right]^{T}
\end{gathered}
$$

where

$$
\begin{gathered}
\mathbf{J}(k, s)=\mathbf{A}_{E}\left(d_{E}\right) \cdot \mathbf{A}_{p}\left(d_{p}\right) \cdot \mathbf{Z}_{H T}, \\
\mathbf{A}_{E}\left(d_{E}\right)=\mathbf{Z}_{E T} \cdot \mathbf{Z}_{E b}^{-1}, \text { and } \mathbf{A}_{p}\left(d_{p}\right)=\mathbf{Z}_{P T} \cdot \mathbf{Z}_{P b}^{-1} .
\end{gathered}
$$

Subscripts $b$ and $T$ stand for base and top of the concerned layer respectively. The $\mathbf{J}$ and $\mathbf{A}$ matrices are also $4 \times 4$ matrices. We use a numerical procedure to evaluate the inverse matrices.

The third and fourth equations contained in the matrix relation (20) can be combined with equation (4) of A1.3 to yield

$$
\begin{gathered}
J_{31} F_{H}+J_{33} D_{H}=0 \\
J_{41} F_{H}+J_{43} D_{H}=\frac{-\rho g h e^{s t} r_{R} J_{1}\left(k r_{R}\right)}{k} .
\end{gathered}
$$

These equations are solved for $D_{H}$ and $F_{H}$. Hence, with $\Delta=J_{31} J_{43}-J_{33} J_{41}$,

$$
\begin{aligned}
{\left[F_{H}, 0, D_{H}, 0\right]^{T}=} & \frac{-\rho g h e^{s t} r_{R} J_{1}\left(k r_{R}\right)}{k} \\
& \times\left[\frac{J_{33}}{\Delta}, 0,-\frac{J_{31}}{\Delta}, 0\right]^{T}, \quad(21 a) \\
{\left[F_{P}, E_{P}, D_{P}, C_{P}\right]^{T} } & =\mathbf{Z}_{P b}^{-1} \cdot \mathbf{Z}_{H T}\left[F_{B}, 0, D_{B}, 0\right]^{T},
\end{aligned}
$$

$\left[F_{E}, E_{E}, D_{E}, C_{E}\right]^{T}=\mathbf{Z}_{E b}^{-1} \mathbf{A}_{P}\left(d_{P}\right) \cdot \mathbf{Z}_{H T}\left[F_{B}, 0, D_{B}, 0\right]^{T}$.

The values of constants so obtained may be substituted into equations (18a-d), (16a-f) and (17a-d).

\section{A4. Results after evaluation of inverse Hankel transform integrals}

The inverse Hankel transform integrals in equations $(17 \mathrm{a}-\mathrm{d}),(16 \mathrm{a}-\mathrm{f})$ and $(18 \mathrm{a}-\mathrm{d})$ are evaluated numerically. The result in each case is complex-valued. It may be written in polar form whose real part can be retained for further use. For example, the result from evaluation of equation (16e) will be of the form

$$
\begin{aligned}
\sigma_{z z P}(\omega t) & =\Re\left[A_{\sigma_{z z P}} e^{\left(s t+\iota \phi_{\sigma_{z z P}}\right)}\right] \\
& =A_{\sigma_{z z P}} \cos \left(\omega t+\phi_{\sigma_{z z P}}\right) .
\end{aligned}
$$

\section{A5. Evaluation of normal stresses $\sigma_{r r P}$ and $\sigma_{\theta \theta P}$}

We follow for $\sigma_{r r P}$, the same procedure as used by Wang (2000, section 9.6) to obtain expressions for $\sigma_{z z P}$ and $\tau_{r z P}$ from those for $u_{r P}$ and $u_{z P}$ with the help of the constitutive equations. Thus, after some simplification, we have in continuation with equations (14a-f),

$$
\begin{aligned}
& \sigma_{r r P}(r, z, t, s)=2 G_{P} \int_{0}^{\infty}\left[k\left(E_{P} e^{k z}+F_{P} e^{-k z}\right)\right. \\
& +b_{1 u P}\left(-k z+2 \nu_{P}\right) D_{P} e^{-k z} \\
& +b_{1 u P}\left(k z+2 \nu_{u P}\right) C_{P} e^{k z} \\
& \left.+\left(\frac{c k^{2}}{s}-1\right) \gamma_{P}\left(A_{P} e^{m z}+B_{P} e^{-m z}\right)\right] J_{0}(k r) k d k \\
& -2 G_{P} \frac{1}{r} \int_{0}^{\infty}\left[\left(E_{P} e^{k z}+F_{P} e^{-k z}\right)\right. \\
& +b_{1 u P} z\left(C_{P} e^{k z}-D_{P} e^{-k z}\right) \\
& \left.+\frac{c k}{s} \gamma_{P}\left(A_{P} e^{m z}+B_{P} e^{-m z}\right)\right] J_{1}(k r) k d k
\end{aligned}
$$


Alternately, in conformity with equations (16a-f),

$$
\begin{aligned}
\sigma_{r r P}(r, & z, t, s)=2 G_{P} \int_{0}^{\infty}\left[k\left(E_{P} e^{k z}+F_{P} e^{-k z}\right)\right. \\
& +\left\{b_{1 u P}\left(k z+2 \nu_{u P}\right)+\left(\frac{c k^{2}}{s}-1\right) \alpha_{C+}\right\} \\
& \times C_{P} e^{k z}+\left\{b_{1 u P}\left(-k z+2 \nu_{u P}\right)\right. \\
& \left.\left.+\left(\frac{c k^{2}}{s}-1\right) \alpha_{D+}\right\} D_{P} e^{-k z}\right] J_{0}(k r) k d k \\
& -2 G_{P} \frac{1}{r} \int_{0}^{\infty}\left[\left\{\left(b_{1 u P} z+\frac{c k}{s} \alpha_{C+}\right) C_{P} e^{k z}\right.\right. \\
& \left.+\left(-b_{1 u P} z+\frac{c k}{s} \alpha_{D+}\right) D_{P} e^{-k z}\right\} \\
& \left.+\left(E_{P} e^{k z}+F_{P} e^{-k z}\right)\right] J_{1}(k r) k d k .
\end{aligned}
$$

Equation (23) can be evaluated using equation (21b).

For evaluating $\sigma_{\theta \theta P}$, using the definition of mean normal stress $\sigma_{M P}$,

$$
\begin{aligned}
\sigma_{\theta \theta P}(r, z, t, s)= & 3 \sigma_{M P}(r, z, t, s)-\sigma_{z z P}(r, z, t, s) \\
& -\sigma_{r r P}(r, z, t, s) .
\end{aligned}
$$

From equation (2.24) of Wang (2000),

$$
\sigma_{M P}(r, z, t, s)=K_{d P} \epsilon_{P}(r, z, t, s)-\alpha_{P} p_{P}(r, z, t, s) .
$$

Also, from equation (9.38) of Wang (2000),

$$
\begin{aligned}
\epsilon_{P}(r, z, t, s)= & \int_{0}^{\infty}\left[\left(D_{P} e^{-k z}+C_{P} e^{k z}\right)\right. \\
& \left.+\gamma\left(A_{P} e^{m z}+B_{P} e^{-m z}\right)\right] J_{0}(k r) k d k .
\end{aligned}
$$

Expressions for $\sigma_{z z P}, \sigma_{r r P}$ and $p_{P}$ have been derived already. The constants in the integral for $\epsilon_{P}$ have also been evaluated above.

\section{A6. Evaluation of the response of NHCEM to mean water load}

The above theory for $h \cos (\omega t)$ may be used to evaluate the response to $H^{\prime}$ by setting $\omega=0$ and $\nu_{u P}=\nu_{d P}$. The second step removes all the terms representing the porous-elastic effects in the $\mathrm{P}$ layer from the above expressions. The remaining terms represent only the elastic effects due to a constant load on NHCEM. The results in table 1 of the main text are obtained in this way from our computer program for evaluating the response at focus due to $h \cos (\omega t)$.

\section{A7. Sign convention}

The above derivations are in conformity with the sign convention adopted by Wang (2000), where compressive normal stress is considered numerically negative. The results quoted in the main text conform to the sign convention of Jaeger and Cook (1969), where compressive normal stress is considered positive.

\section{Appendix B}

\section{Symbols}

$b_{1 j}=\frac{1}{2\left(1-2 \nu_{j}\right)}, j=\mathrm{E}, \mathrm{H}$

$b_{2 j}=\frac{3-4 \nu_{j}}{2\left(1-2 \nu_{j}\right)}, j=\mathrm{E}, \mathrm{H}$

$b_{4 j}=\frac{1-\nu_{j}}{\left(1-2 \nu_{j}\right)}, j=\mathrm{E}, \mathrm{H}$

$b_{1 j P}=\frac{1}{\left(2\left(1-2 \nu_{j P}\right)\right.}, j=\mathrm{u}$ (undrained) or $\mathrm{d}$

(drained)

$b_{2 j P}=\frac{3-4 \nu_{j P}}{2\left(1-2 \nu_{j P}\right)}, j=\mathrm{u}$ or $\mathrm{d}$

$b_{4 j P}=\frac{1-\nu_{j} P}{\left(1-2 \nu_{j P}\right)}, j=\mathrm{u}$ or $\mathrm{d}$

$b_{5 P}=\frac{1-\nu_{d P}}{\alpha_{P}\left(1-2 \nu_{d P}\right)}$

$c_{P}$ : hydraulic diffusivity in $\mathrm{P}$ layer;

$d_{j}$ : thickness of $j=\mathrm{E}, \mathrm{P}$, and $\mathrm{H}$ layers

$h$ : amplitude of annual oscillation in water depth

$k$ : wave number along $r$ direction

$m=\sqrt{k^{2}+\frac{s}{c_{P}}}$

$p$ : pore pressure

$p_{P}$ : pore pressure at a point in $\mathrm{P}$ layer

$r$ : radial coordinate

$s=\iota \omega$

$t$ : time

$u_{r}, u_{z}$ : displacement components along $r$ and $z$ directions

$z$ : coordinate along z-axis

$A_{j}, B_{j}, C_{j}, D_{j}, E_{j}, F_{j}$ : arbitrary constants in the general solution of field equations for $j=\mathrm{E}, \mathrm{P}, \mathrm{H}$ layers

$B_{P}$ : Skempton's coefficient in $\mathrm{P}$ layer;

$B_{P}=\frac{3\left(\nu_{u P}-\nu_{d P}\right)}{\alpha\left(1-2 \nu_{d P}\right)\left(1+\nu_{u P}\right)}$ (Wang 2000)

$\mathrm{E}, \mathrm{P}$ or $\mathrm{H}$ : the elastic, porous-elastic or half-space layer

$G_{j}$ : shear modulus of $j=\mathrm{E}, \mathrm{P}$ and $\mathrm{H}$ layers

$H^{\prime}$ : annual mean depth of water in the reservoir

$J_{0}, J_{1}$ : Bessel Functions of order 0,1

$K_{u P}$ : undrained bulk modulus in P layer;

$K_{u P}=\frac{2 G_{P}\left(1+\nu_{u P}\right)}{3\left(1-2 \nu_{u P}\right)}$ 
$K_{d P}$ : drained bulk modulus in P layer;

$K_{d P}=\frac{2 G_{P}\left(1+\nu_{d P}\right)}{3\left(1-2 \nu_{d P}\right)}$

$S(\omega t)$ : fault stability at reservoir phase $\omega t$

$S_{R}(\omega t)$ : fault stability under reservoir influence at phase $\omega t$

$S_{T}(\omega t)$ : fault stability under tectonic influence at phase $\omega t$

$\alpha_{P}$ : Biot-Willis coefficient in $\mathrm{P}$ layer

$\gamma_{P}=\frac{\nu_{u P}-\nu_{d P}}{\alpha\left(1-2 \nu_{d P}\right)\left(1-\nu_{u P}\right)}($ Wang 2000)

$\epsilon_{j}$ : volumetric strain in $j=\mathrm{E}, \mathrm{P}$ and $\mathrm{H}$ layers

$\zeta_{P}$ : increment of fluid content in $\mathrm{P}$ layer

$\nu_{j}$ : Poisson's ratio of $j=\mathrm{E}$ and $\mathrm{H}$ layers

$\nu_{j P}, j=\mathrm{u}$ or $\mathrm{d}$ : undrained or drained Poisson's

ratio in $\mathrm{P}$ layer

$\phi$ : angle of rock friction

$\sigma$ : normal stress component

$\sigma_{M P}$ : mean normal stress in $\mathrm{P}$ layer

$\sigma_{r r j}$ : radial normal stress component in $j=\mathrm{E}, \mathrm{P}$, $\mathrm{H}$ layers

$\sigma_{z z j}$ : vertical normal stress component in $j=\mathrm{E}, \mathrm{P}$, $\mathrm{H}$ layers

$\sigma^{\prime}$ : effective normal stress $(=\sigma \pm \alpha p$, where $\sigma$ is a normal stress component; + sign for Appendix A and - sign for main text. For use of factor $\alpha$, see Wang (2000)

$\tau_{r z j}$ : shear stress component in $j=\mathrm{E}, \mathrm{P}, \mathrm{H}$ layer $\tau_{s}$ : reservoir-induced resolved shear stress on fault plane along strike

$\tau_{d}$ : reservoir-induced resolved shear stress on fault plane along dip

$\omega$ : angular frequency of reservoir operation

\section{References}

Haskell N A 1953 Dispersion of surface waves on multilayered media; Bull. Seismol. Soc. Am. 43 17-43.

Hubbert M K and Rubey W W 1959 Role of fluid pressure in the mechanics of overthrust faulting; Bull. Geol. Soc. Am. 70 115-205.

Jaeger J C and Cook N G W 1969 Fundamentals of Rock Mechanics; Methuen, London, 515p.

Love A E H 1944 A Treatise on the Mathematical Theory of Elasticity; Dover Publications, New York, 643p.

Richter C F 1957 Elementary Seismology; W H Freeman and Company, San Francisco, 768p.

Roeloffs E A 1988 Fault stability changes induced beneath a reservoir with cyclic variations in water level; J. Geophys. Res. 93(B3) 2107-2124.

Rogers A M and Lee W H K 1976 Seismic study of earthquakes in the Lake Mead, Nevada-Arizona region; Bull. Seismol. Soc. Am. 66 1657-1683.

Segall P 1985 Stress and subsidence resulting from fluid withdrawal in epicentral region of the 1983 Coalinga earthquake; J. Geophys. Res. 90 6801-6816.

Singh S J and Rani S 2006 Plane strain deformation of a multi-layered poroelastic half-space; J. Earth Syst. Sci. 115 685-694.

Singh S J, Kumar R and Rani S 2009 Consolidation of a poroelastic half-space with anisotropic permeability and compressible constituents by axisymmetric surface loading; J. Earth Syst. Sci. 118(5) 563-574.

Sneddon I N 1951 Fourier Transforms; McGraw-Hill Book Company Inc., New York, 541p.

Snow D T 1972 Geodynamics of seismic reservoirs; Proc. Flow Fractured Rock; German Soc. Soil Rock Mech. T2-J 19.

Talwani P and Acree S 1985 Pore pressure diffusion and mechanism of reservoir induced seismicity; PGEOPH 122 947-965.

Talwani P 1997 On the nature of reservoir-induced seismicity; PGEOPH 150 473-492.

Wang H F 2000 Theory of Linear Poroelasticity with Applications to Geomechanics and Hydrogeology; Princeton University Press, Princeton, 287p. 